\title{
TITLE:
}

\section{Control of electrostatic charge on particles by impact charging}

$\operatorname{AUTHOR}(\mathrm{S})$ :

Matsusaka, Shuji; Oki, Mitsuhiro; Masuda, Hiroaki

\section{CITATION:}

Matsusaka, Shuji ...[et al]. Control of electrostatic charge on particles by impact charging. Advanced Powder Technology 2007, 18(2): 229-244

\section{ISSUE DATE:}

2007-03-01

URL:

http://hdl.handle.net/2433/194295

\section{RIGHT:}

(c) 2007 Published by Elsevier B.V.; NOTICE: this is the author's version of a work that was accepted for publication in Advanced Powder Technology. Changes resulting from the publishing process, such as peer review, editing, corrections, structural formatting, and other quality control mechanisms may not be reflected in this document. Changes may have been made to this work since it was submitted for publication. A definitive version was subsequently published in Advanced Powder Technology, 18(2) 229-244, 2007, doi:10.1163/156855207780208673; この論文は出版社版でありませ ん。引用の際には出版社版をご確認ご利用ください。; This is not the published version. Please cite only the published version. 


\title{
Control of electrostatic charge on particles by impact charging
}

\author{
SHUJI MATSUSAKA*, MITSUHIRO OKI and HIROAKI MASUDA \\ Department of Chemical Engineering, Kyoto University, \\ Kyoto 615-8510 Japan
}

Japanese version published in JSPTJ, Vol. 43, No. 3 (2006);

English version for APT received 17 October 2006.

\begin{abstract}
The control of electrostatic charge on particles in gas-solids pipe flow has been studied experimentally and theoretically. Alumina particles of $3.3 \mu \mathrm{m}$ in count median diameter were dispersed in airflow and pneumatically transported in the dilute phase. Five different materials were used for the transport pipes, and the relationships between the particle charge and the pipe length were obtained. The polarity and the amount of particle charge were found to depend on the pipe material and the length. In order to control the particle charge, a system combining two different pipe materials was proposed depending on the particle-charging characteristics. The charge controlled by this method was in good agreement with the theoretical calculation. Furthermore, it was found that the distribution of particle charge as well as the average can be controlled.
\end{abstract}

Keywords: Electrostatics; impact charging; charge control; gas-solids pipe flow; charge distribution

*To whom correspondence should be addressed. E-mail: matsu@cheme.kyoto-u.ac.jp 


\section{NOMENCLATURE}

\begin{tabular}{|c|c|}
\hline$f_{\mathrm{qm}}$ & probability density function of specific charge $(\mathrm{kg} / \mathrm{C})$ \\
\hline$f_{\sigma \mathrm{q}}$ & probability density function of surface charge density $\left(\mathrm{m}^{2} / \mathrm{C}\right)$ \\
\hline$L$ & pipe length (m) \\
\hline$L_{0}$ & characteristic length of impact charging $\square$ (m) \\
\hline$n$ & number of particle impacts $(-)$ \\
\hline$n_{0}$ & characteristic number of impact charging (-) \\
\hline$q$ & particle charge $(\mathrm{C})$ \\
\hline$q_{\mathrm{m}}$ & specific charge of particles, i.e. charge-to-mass ratio (C/kg) \\
\hline $\bar{q}_{\mathrm{m}}$ & average specific charge of particles (C/kg) \\
\hline $\bar{q}_{\mathrm{m}} *$ & limiting value of specific charge of particles $(\mathrm{C} / \mathrm{kg})$ \\
\hline$r$ & pipe length ratio of $A$ to $B$ or surface coverage ratio of $A$ to $B(-)$ \\
\hline $\bar{u}$ & average air velocity (m/s) \\
\hline \multicolumn{2}{|c|}{ Greek } \\
\hline$\gamma_{\mathrm{q}}$ & Particle charge fraction $(-)$ \\
\hline$\sigma_{\mathrm{q}}$ & surface charge density $\left(\mathrm{C} / \mathrm{m}^{2}\right)$ \\
\hline \multicolumn{2}{|c|}{ Subscripts } \\
\hline 0 & initial value \\
\hline$\infty$ & equilibrium value \\
\hline A & wall material A \\
\hline $\mathrm{B}$ & wall material B \\
\hline $\mathrm{N}$ & number of units consisting of two charging pipes $A$ and $B$ \\
\hline
\end{tabular}




\section{INTRODUCTION}

Particles are often electrostatically charged by contact with walls during powder-handling operations, and the electrostatic charge causes problems such as particle deposition and adhesion [1-3]. Also, when particles are charged excessively, electrostatic discharge will occur, and cause fire and explosion hazards [4, 5]; thus, it is important to clarify the contact charging between different materials [6-9]. Research on the impact charging of particles on a plate [10-14] and the charge transfer in gas solids pipe flow [15-20] enables us to understand the particle-charging mechanism to a certain extent; however, it is still difficult to control the charge on particles with high precision.

In general, the control method of the charge on particles is divided into (i) electrostatic discharging such as self-discharging [21] and neutralization by adding ions of opposite polarity and (ii) electrostatic charging such as corona charging and tribo-charging [23, 24]; however, there are few reports on the simultaneous control of charging and discharging.

When particles are charged by impact on a wall, the polarity of the charge on particles depends on the wall material. Also, for a mixture of different kinds of particles, electrostatic separation is carried out using the difference in the polarity of the charge obtained by repeated impacts [25-27]. Applying such knowledge and experience, the charge on particles may be controlled by impact charging; however, the details of the methods to control the charge and to evaluate the factors required for the system are not established yet.

In the present paper, in order to study particle charging caused by repeated impacts on a different wall, we pay attention to the charging in dilute-phase gas-solids pipe flow. The results obtained using five kinds of pipes are quantitatively analyzed by a theoretical model of the particle-charging process. On the basis of the above consideration, we present a charge control method using two different wall materials, in which the distribution of particle charge as well as the average is studied.

\section{EXPERIMENTAL APPARATUS AND PROCEDURES}

Figure 1 shows a schematic diagram of the experimental apparatus. Micrometer-sized particles were continuously fed using a table feeder (MFOV-1, Sankyo Pio-tech). To 
improve the continuous stability of powder feeding at a low flow rate, we applied a method to suck the particles directly from the powder bed formed on the rotating table into a capillary tube less than $1 \mathrm{~mm}$ in inner diameter $[18,19]$. The air that was supplied from a compressor was dried through a condenser and maintained at a relative humidity of $10 \%$. The particles were dispersed into the airflow through an ejector (VRL 50-080108, Nihon Pisco). Charging pipes were 6 mm in inner diameter, 0.5, 1, 2, and $3 \mathrm{~m}$ long, and made of five different materials, i.e. two kinds of stainless steel (JIS, SUS 316 and SUS 304), aluminum, copper, and brass. The pipes were formed in a spiral to increase the efficiency of particle charging; the radius of the curvature was 80 $\mathrm{mm}$. The average air velocity in the pipes was maintained at $40 \mathrm{~m} / \mathrm{s}$, in which no particle deposition layer was formed. To avoid the effect of contacts or impacts between particles on particle charging, all the experiments were conducted at a low

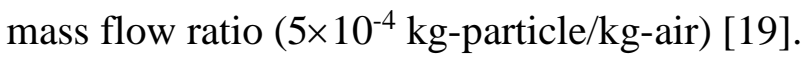

The charge and mass of each particle were measured at the inlet and outlet of the charging pipe using an electrical single-particle aerodynamic relaxation time analyzer (E-SPART analyzer, Hosokawa Micron). The number of particles sampled for each measurement was over 6000. The charging pipe was connected to the ejector with a polyurethane tube. Although there was no special technique for the control of particle charge at the inlet of the charging pipe, the charge was less than $0.1 \mathrm{mC} / \mathrm{kg}$, which was sufficiently small as compared to the charge obtained in the charging pipe.

The powders used were alumina, $3.3 \mu \mathrm{m}$ count median diameter, 1.6 geometric standard deviation, and particle density $4000 \mathrm{~kg} / \mathrm{m}^{3}$. A scanning electron microscopy (SEM) image of the particles is shown in Fig 2. These particles were dried at $110^{\circ} \mathrm{C}$ over $12 \mathrm{~h}$ and cooled down to room temperature in a desiccator.

\section{RESULTS AND DISCUSSION}

\subsection{Effect of wall material on particle charging}

Figure 3 shows the relationships between the average of the specific charge of particles

$\bar{q}_{\mathrm{m}}$ and the pipe length $L$, which were obtained from the experiments using the five different kinds of charging pipes. The particles were charged positively by contact with the walls of the two kinds of stainless steel, i.e. SUS 316 and SUS 304, and no 
distinct difference was observed in the levels of particle charging. As for aluminum, copper, and brass, the particles were charged negatively, in which the charging level for the aluminum pipe was rather small. The absolute value of the specific charge increased with the pipe length but the rate of increase gradually decreased and the charge approached an equilibrium value corresponding to the wall material.

According to a theoretical model of the charge on a particle obtained by repeated impacts on a metal wall, the particle charge $q$ is represented by [11, 29].

$$
\left.q(n)=q_{0} \exp \left(-\frac{n}{n_{0}}\right)+q_{\infty}\left\{1-\exp \left(-\frac{n}{n_{0}}\right)\right\}\right\}
$$

where $q_{0}$ is the initial charge of the particle at $n=0, q_{\infty}$ is the equilibrium charge at $n=\infty$, $n$ is the number of impacts, and $n_{0}$ is the characteristic number depending on the state of contact between the particle and the wall.

Each particle in a powder usually has a different diameter; thus, the amount of particle charge is not constant. In order to formulate the particle charging in gas-solids pipe flow, the average specific charge $\bar{q}_{\mathrm{m}}$ should be used instead of the charge on a particle $q$. Although the number of impacts $n$ is an important factor for particle charging, it is difficult to measure the number of impacts in the pipe. When the flow in the pipe is fully developed, the frequency of the particle-wall impacts per unit pipe length will be constant, and the number of impacts $n$ is proportional to the pipe length $L$. Therefore, the average specific charge $\bar{q}_{\mathrm{m}}$ can be represented by:

$$
\left.\bar{q}_{\mathrm{m}}(L)=\bar{q}_{\mathrm{m} 0} \exp \left(-\frac{L}{L_{0}}\right)+\bar{q}_{\mathrm{m} \infty}\left\{1-\exp \left(-\frac{L}{L_{0}}\right)\right\}\right\}
$$

where $\bar{q}_{\mathrm{m} 0}$ and $\bar{q}_{\mathrm{m} \infty}$ are, respectively, the initial and equilibrium values of the average specific charge, and $L_{0}$ is the characteristic length of the particle charging.

The curves in Fig. 3 are obtained by fitting the experimental data to (2). The experimental results are found to be in good agreement with the calculated ones. In these calculations, $\bar{q}_{\mathrm{m} 0}$ is supposed to be zero, and the values of $\bar{q}_{\mathrm{m} \infty}$ and $L_{0}$ are listed in Table 1. $\bar{q}_{\mathrm{m} \infty}$ was in the range from -8.6 to $7.5 \mathrm{mC} / \mathrm{kg}, L_{0}$ was from 0.63 to $1.13 \mathrm{~m}$, and these values varied depending on the wall materials, i.e. stainless steel $>$ brass $>$ copper $>$ aluminum. The order agrees qualitatively with that of the hardness of the 
materials. This is probably caused by the contact area between a particle and a wall. Since the contact area decreases with the increase in the hardness of the surface, the number of impacts for particle charging is larger for a harder surface.

Also, particle charge fraction $\gamma_{q}$ (the level of charge) is derived from (2), i.e.:

$$
\gamma_{\mathrm{q}}=\frac{\bar{q}_{\mathrm{m}}-\bar{q}_{\mathrm{m} 0}}{\bar{q}_{\mathrm{m} \infty}-\bar{q}_{\mathrm{m} 0}}=1-\exp \left(-\frac{L}{L_{0}}\right)
$$

Substituting $L=3 \mathrm{~m}$ and the characteristic values of $L_{0}$ listed in Table 1 into (3) gives the particle charge fraction for the maximum pipe length in this experiment, e.g. $\gamma_{\mathrm{q}}=$ 93\% for SUS316 and 99\% for aluminum, and the facts show that the particle charge is almost in equilibrium at $L=3 \mathrm{~m}$.

Figure 4 shows the charge distributions of alumina particles after passing through different lengths of stainless steel pipes. Although the average specific charge for $L=0$ is nearly zero, the values of particle charge are found to be widely distributed, including both positive and negative charges. The fraction of positively charged particles increases with the pipe length; however, there is little difference in the distributions over $2 \mathrm{~m}$. This also shows that the particle charge is almost in equilibrium.

Figure 5 shows the effect of the wall material on the distribution of the surface charge density of particles. The charge distributions for two kinds of stainless steel pipes are similar to each other. The common characteristic features are as follows; the median value of the charge distribution is positive and the distribution curve is symmetrical. For the aluminum pipe, the median value is nearly zero; however, the distribution curve is extended toward a negative charge. As for copper and brass, the charge distribution curves are very different from those mentioned above; i.e. they are obviously asymmetrical and many particles were charged negatively. Here, it is worth noting that the polarity and the distribution of the particle charge depends on the wall material, and the maximum absolute value of surface charge density is as large as $6 \times 10^{-5} \mathrm{C} / \mathrm{m}^{2}$.

\subsection{Effect of initial charge on particle charging}

The polarity and the amount of the charge on particles can be changed 
depending on the wall material. To systematically study the particle charging, we performed a series of experiments; i.e., particles were pre-charged by the first pipe and charged by the second pipe made of different material. Figure 6(a) shows the results obtained using brass for the first pipe and stainless steel (SUS316) for the second pipe. The initial charge of particles entering the second pipe can be changed by the length of the first pipe. The particles obtain positive charge by contact with the stainless steel, and the amount of transferred charge increases with the amount of the negative initial charge. Fig 6(b) shows the results obtained using the pipes arranged in the reverse order. Although the polarity of the charge is different from that in Fig. 6(a), the qualitative feature of the charge transfer is similar.

To discuss the charge transfer, we focus on the variation of the average specific charge $\bar{q}_{\mathrm{m}}$ with respect to the pipe length $L$. The differential equation is derived from (2), i.e.:

$$
\frac{d \bar{q}_{\mathrm{m}}}{d L}=\frac{\bar{q}_{\mathrm{m} \infty}-\bar{q}_{\mathrm{m} 0}}{L_{0}} \exp \left(-\frac{L}{L_{0}}\right) .
$$

Since $d \bar{q}_{\mathrm{m}} / d L$ is proportional to $\bar{q}_{\mathrm{m} \infty}-\bar{q}_{\mathrm{m} 0}$, the charge transferred per unit length increases with the initial charge $\bar{q}_{\mathrm{m} 0}$ if the polarity of $\bar{q}_{\mathrm{m} 0}$ is different from that of the equilibrium charge $\bar{q}_{\text {mo }}$.

The curves obtained by fitting the experimental data to (2) are also shown in Fig. 6. The values used for the calculations are listed in Table 2. For SUS316, $\bar{q}_{\text {mo }}$ ranges from 6.7 to $7.5 \mathrm{~m} \mathrm{C} / \mathrm{kg}, L_{0}$ ranges from 0.90 to $1.15 \mathrm{~m}$. As for brass, $\bar{q}_{\text {mo }}$ ranges from -8.1 to $-8.6 \mathrm{mC} / \mathrm{kg}, L_{0}$ ranges from 0.76 to $0.97 \mathrm{~m}$. The values show a tendency that a larger amount of initial charge $\bar{q}_{\mathrm{m} 0}$ gives a smaller amount of equilibrium charge $\bar{q}_{\text {mo }}$ and smaller characteristic length $L_{0}$. These facts suggest that highly pre-charged particles hold a part of the initial charge. On the other hand, such highly pre-charged particles easily release the charges in the early stage and therefore the characteristic length $L_{0}$ is shorter.

\subsection{Comparison between theory and experimental results}


Figure 7 shows all the data obtained from the system connecting the first and second pipes in series. In Fig. 7 (a), the first pipe is brass and the second pipe is SUS316, while the first pipe is SUS316 and the second pipe is brass in Fig. 7 (b). The open symbols represent the data for SUS316 and the closed symbols are for brass. The lines are calculated using (2) with the average values listed in the last column of Table 2. The solid lines and the dotted lines correspond to the data for SUS316 and for brass, respectively. The calculated lines are well fit to these data even though an average value is used instead of the best-fit values for each data, which strongly supports that (2) represents the main feature of the electrification process of particles.

\subsection{Control of charge on particles}

The above results suggest the possibility that the charge on particles is controlled within a desired region, based on the equilibrium charges determined by two different kinds of pipes.

Figure 8(a) shows the experimental results for the specific charge obtained by connecting 1-m brass pipe and 1-m SUS316 pipe alternately. The particles are charged negatively in the brass pipes but positively in the SUS316 pipes. As a result of this tendency, the values of the specific charge are within a certain range. On the other hand, Fig. 8(b) shows the results obtained using the pipes arranged in the reverse order. The lines in these fig. 8 are calculated by (2), showing good agreement with experimental data.

Figure 9 gives the results obtained by 0.5 -m pipes instead of 1-m pipes in Fig. 8. It is clear that the specific charge in Fig. 9 is within a narrower range as compared to that in Fig. 8, and the calculated lines are well fit to these data.

Although the specific charge is affected by the initial charge at the early stage of this system, the upper and lower limits of the particle charge settle at constant values after passing through several pipes connected in series. The upper limit $\bar{q}{ }_{\mathrm{mA}}{ }^{*}$ for pipe A and the lower limit $\bar{q} \mathrm{mB}^{*}$ for pipe B are given by (see Appendix A): 


$$
\begin{gathered}
\bar{q}_{\mathrm{mA}} *=\frac{\bar{q}_{\mathrm{mA \infty}}\left\{1-\exp \left(-\frac{\Delta L_{\mathrm{A}}}{L_{\mathrm{A} 0}}\right)\right\}+\bar{q}_{\mathrm{mB} \infty} \exp \left(-\frac{\Delta L_{\mathrm{A}}}{L_{\mathrm{A} 0}}\right)\left\{1-\exp \left(-\frac{\Delta L_{\mathrm{B}}}{L_{\mathrm{B} 0}}\right)\right\}}{1-\exp \left(-\frac{\Delta L_{\mathrm{A}}}{L_{\mathrm{A} 0}}-\frac{\Delta L_{\mathrm{B}}}{L_{\mathrm{B} 0}}\right)} \\
\bar{q}_{\mathrm{mB}} *=\frac{\bar{q}_{\mathrm{mB} \infty}\left\{1-\exp \left(-\frac{\Delta L_{\mathrm{B}}}{L_{\mathrm{B} 0}}\right)\right\}+\bar{q}_{\mathrm{mA} \infty} \exp \left(-\frac{\Delta L_{\mathrm{B}}}{L_{\mathrm{B} 0}}\right)\left\{1-\exp \left(-\frac{\Delta L_{\mathrm{A}}}{L_{\mathrm{A} 0}}\right)\right\}}{1-\exp \left(-\frac{\Delta L_{\mathrm{A}}}{L_{\mathrm{A} 0}}-\frac{\Delta L_{\mathrm{B}}}{L_{\mathrm{B} 0}}\right)}
\end{gathered}
$$

where $\Delta L_{\mathrm{A}}$ and $\Delta L_{\mathrm{B}}$ are the pipe lengths, $L_{\mathrm{A} 0}$ and $L_{\mathrm{B} 0}$ are the characteristic lengths, and the subscripts A and B denote the pipes A and B, respectively.

As the pipe length $\Delta L_{\mathrm{A}}, \Delta L_{\mathrm{B}} \rightarrow 0$, the limiting values of the charge satisfy the relation: $\bar{q}_{\mathrm{m}} *=\bar{q}_{\mathrm{mA}} *=\bar{q}_{\mathrm{mB}} *$ In the case that the length of the pipes $\mathrm{A}$ is different from that of the pipes B, the limiting value $\bar{q}_{\mathrm{m}}$ * depends on the ratio of pipe length $r$. Substituting $\Delta L_{\mathrm{A}}=r \Delta L_{\mathrm{B}}$ into (5) and setting $\Delta L_{\mathrm{A}}, \Delta L_{\mathrm{B}} \rightarrow 0$, the limiting value $\bar{q}_{\mathrm{m}} *$ is given by (see Appendix B):

$$
\bar{q}_{\mathrm{m}} *=\frac{\bar{q}_{\mathrm{mA} \infty} r L_{\mathrm{B} 0}+\bar{q}_{\mathrm{mB} \infty} L_{\mathrm{A} 0}}{L_{\mathrm{A} 0}+r L_{\mathrm{B} 0}}
$$

If the inner surface of the pipe is composed of two materials A and B with a certain surface coverage ratio $r$ at any position, the condition of $\Delta L_{\mathrm{A}}, \Delta L_{\mathrm{B}} \rightarrow 0$ is satisfied and the final average specific charge $\bar{q}_{\mathrm{m}}{ }^{*}$ can be controlled.

\subsection{Control of charge distribution}

Figure 10 shows the effect of the above method for the control of the charge distribution of particles. The closed circles and triangles show the experimental data obtained using a 4-m pipe constituted by connecting 1-m brass pipe and 1-m SUS316 pipe alternately. The data denoted by the circles are for the connection order of brass, SUS316, brass and SUS316, while the triangles are for the order of SUS316, brass, SUS316, and brass. For reference, the data obtained by a 3-m SUS316 pipe and a 3-m brass pipe are shown by open circles and triangles, respectively. The charge distributions shown by the closed symbols are narrower than the distribution shown by 
the open symbols, i.e. the present charge control method makes the charge distribution of particles narrower.

\section{CONCLUSIONS}

Electrostatic charge on particles in dilute phase gas-solids pipe flow has been studied with alumina particles of $3.3 \mu \mathrm{m}$ in count median diameter. In order to obtain the basic information on the control of the particle charge, average specific charge and the charge distribution have been studied in detail using the transport pipes made of different materials. The results obtained are summarized as follows:

(i) The polarity of the average specific charge of particles depends on the wall material of the transport pipe; alumina particles were charged positively for the stainless steel pipes, while they were charged negatively for the aluminum, copper, and brass pipes.

(ii) The amount of average specific charge increases with the pipe length. The rate of increase in the particle charge decreases gradually, and the charge approaches a unique equilibrium value corresponding to the pipe material. The average specific charge is found to be represented by an exponential function of the pipe length, which makes it possible to quantitatively evaluate particle charging.

(iii) Even though the average specific charge is zero, the values of particle charge are found to be widely distributed, including both positive and negative charges. The charge distribution as well as the average charge varies depending on the pipe length and the material.

(iv) The average specific charge can be maintained within a certain range by connecting different kinds of pipes alternately, and the range is narrower as the length of each pipe is shorter. The distribution of particle charge is also controlled by this method.

\section{Acknowledgements}

The authors gratefully acknowledge support for this research by Kyoto Prefecture Collaboration of Regional Entities for the Advancement of Technological Excellence, JST. 


\section{REFERENCES}

1. S. Joseph and G. E. Klinzing, Vertical gas-solid transition flow with electrostatics, Powder Technol. 36, 79-87 (1983).

2. I. Adhiwidjaja, S. Matsusaka, S. Yabe and H. Masuda, Simultaneous phenomenon of particle deposition and reentrainment in charged aerosol flow — effects of particle charge and external electric field on the deposition layer, Adv. Powder Technol. 11, 221-233 (2000).

3. J. Yao, Y. Zhang, C-H. Wang, S. Matsusaka, and H. Masuda, Electrostatics of the granular flow in a pneumatic conveying system, Ind. Eng. Chem. Res. 43, 7181-7199 (2004).

4. A. Ohsawa, Computer simulation for assessment of electrostatic hazards in filling operations with powder, Powder Technol. 135-136, 216-222 (2003).

5. M. Nifuku and H. Katoh, A study on the static electrification of powders during pneumatic transportation and the ignition of dust cloud, Powder Technol. 135-136, 234-242 (2003).

6. W. R. Harper, The Volta effect as a cause of static electrification, Proc. R. Soc. A 205, 83-103 (1951).

7. W. R. Harper, Contact and Frictional Electrification, Clarendon Press, Oxford (1967).

8. D. K. Davies, Charge generation on dielectric surfaces, Br. J. Appl. Phys: J. Phys. D 2, 1533-1537 (1969).

9. J. Lowell and A.C. Rose-Innes, Contact electrification, Adv. Phys. 29, 947-1023 (1980).

10. H. Masuda and K. Iinoya, Electrification of particles by impact on inclined metal plates, AIChE J. 24, 950-956 (1978).

11. S. Matsusaka, M. Ghadiri and H. Masuda, Electrification of an elastic sphere by repeated impacts on a metal plate, J. Phys. D: Appl. Phys. 33, 2311-2319 (2000).

12. A. Ema, D. Yasuda, K. Tanoue and H. Masuda, Tribo-charge and rebound characteristics of particles impact on inclined or rotating metal target, Powder Technol. 135-136,: 2-13 (2003).

13. T. Matsuyama, M. Ogu, H. Yamamoto, J. C. M. Marijnissen, B. Scarlett, 
Impact charging experiments with single particles of hundred micrometre size, Powder Technol. 135-136, 14-22 (2003).

14. M. Yoshida, A. Shimosaka, Y. Shirakawa, J. Hidaka, T. Matsuyama, H. Yamamoto, Estimation of electrostatic charge distribution of flowing toner particles in contact with metals, Powder Technol. 135-136, 23-34 (2003).

15. B. N. Cole, M. R. Baum and F. R. Mobbs, An investigation of electrostatic charging effects in high-speed gas-solids pipe flows, Proc. Inst. Mech. Eng. 184, 77-83 (1969-1970).

16. H. Masuda, T. Komatsu and K. Iinoya, The static electrification of particles in gas-solids pipe flow, AIChE J. 22 558-564 (1976).

17. N. Masui and Y. Murata, Electrification of polymer powders after passage through metal pipes, Jpn. J. Appl. Phys. 23, 110-117 (1984).

18. S. Matsusaka, H. Umemoto, M. Nishitani and H. Masuda, Electrostatic charge distribution of particles in gas-solids pipe flow, J. Electrostat. 55, 81-96 (2002).

19. S. Matsusaka, M. Oki, H. Masuda, Bipolar charge distribution of a mixture of particles with different electrostatic characteristics in gas-solids pipe flow, Powder Technol. 135-136, 150-155 (2003).

20. S. Watano, S. Saito, T. Suzuki, Numerical simulation of electrostatic charge in powder pneumatic conveying process, Powder Technol. 135-136, 112-117 (2003).

21. H. Masuda, A. Kobayashi and K. Iinoya, Neutralization of charged particles by self-discharge, J. Soc. Powder Technol., Japan. 18, 240-243 (1981).

22. T. Kodama, M. Yamaguma, T. Suzuki, T. Mogami and S. Watano, Electrostatic charge reduction performance of passive-type electrostatic eliminator for pneumatic powder transport, J. Inst. Electrostat. Japan. 29, 44-49 (2005).

23. J. F. Hughes, Electrostatic Powder Coating, Research Studies Press, Wiley, New York (1984).

24. A. G. Bailey, The science and technology of electrostatic powder spraying, transport and coating, J. Electrostat. 45, 85-120 (1998).

25. R. Gupta, D. Gidaspow and D. T. Wasan, Electrostatic separation of powder 
mixtures based on the work functions of its constituents, Powder Technol. 75, 79-87 (1993).

26. D. K. Yanar and B. A. Kwetkus, Electrostatic separation of polymer powders, J. Electrostat. 35, 257-266 (1995).

27. T. Takeshita, T. Harada, S. Takeichi and T. Saito, The continuous triboelectric separation for plastic sheets, J. Soc. Powder Technol., Japan 37, 594-597 (2000).

28. M. K. Mazumder, R, E., Ware, T. Yokoyama, B. J. Rubin and D. Kamp, Measurement of particle size and electrostatic charge distributions on toners using E-SPART analyzer, IEEE Trans. Indust. Appl. 27, 611-619 (1991).

29. S. Matsusaka and H. Masuda, Electrostatics of particles, Adv. Powder Technol. 14, 143-166 (2003). 


\section{APPENDIX A}

A charge control system is composed of the same units consisting of two charging pipes A and B connected in series. $\bar{q}_{\mathrm{mAN}}$ and $\bar{q}_{\mathrm{mBN}}$ define the average specific charge of particles at the outlet of the pipe A and B, respectively, in the $N$-th unit, and the latter is given by:

$$
\begin{aligned}
\bar{q}_{\mathrm{mBN}} & =\bar{q}_{\mathrm{mB} \infty}\left\{1-\exp \left(-\frac{\Delta L_{\mathrm{B}}}{L_{\mathrm{B} 0}}\right)\right\}+\bar{q}_{\mathrm{mAN}} \exp \left(-\frac{\Delta L_{\mathrm{B}}}{L_{\mathrm{B} 0}}\right) \\
& =\bar{q}_{\mathrm{mB} \infty}+\left(\bar{q}_{\mathrm{mAN}}-\bar{q}_{\mathrm{mB} \infty}\right) \exp \left(-\frac{\Delta L_{\mathrm{B}}}{L_{\mathrm{B} 0}}\right)
\end{aligned}
$$

In the same way, the average specific charge for the pipe A in the $N+1$-th unit $\bar{q}_{\mathrm{mAN}+1}$ is given by:

$$
\begin{aligned}
\bar{q}_{\mathrm{mAN}+1} & =\bar{q}_{\mathrm{mA} \infty}\left\{1-\exp \left(-\frac{\Delta L_{\mathrm{A}}}{L_{\mathrm{A} 0}}\right)\right\}+\bar{q}_{\mathrm{mBN}} \exp \left(-\frac{\Delta L_{\mathrm{A}}}{L_{\mathrm{A} 0}}\right) \\
& =\bar{q}_{\mathrm{mA} \infty}+\left(\bar{q}_{\mathrm{mBN}}-\bar{q}_{\mathrm{mA} \infty}\right) \exp \left(-\frac{\Delta L_{\mathrm{A}}}{L_{\mathrm{A} 0}}\right)
\end{aligned}
$$

Substituting (A-1) into (A-2) and using the relation of $\bar{q}_{\mathrm{mA}} *=\bar{q}_{\mathrm{mAN}}=\bar{q}_{\mathrm{mAN}+1}$ give:

$$
\begin{aligned}
\bar{q}_{\mathrm{mA}} * & =\bar{q}_{\mathrm{mA} \infty}+\left\{\bar{q}_{\mathrm{mB} \infty}+\left(\bar{q}_{\mathrm{mA}} *-\bar{q}_{\mathrm{mB} \infty}\right) \exp \left(-\frac{\Delta L_{\mathrm{B}}}{L_{\mathrm{B} 0}}\right)-\bar{q}_{\mathrm{mA} \infty}\right\} \exp \left(-\frac{\Delta L_{\mathrm{A}}}{L_{\mathrm{A} 0}}\right) \\
& =\frac{\bar{q}_{\mathrm{mA} \infty}\left\{1-\exp \left(-\frac{\Delta L_{\mathrm{A}}}{L_{\mathrm{A} 0}}\right)\right\}+\bar{q}_{\mathrm{mB} \infty} \exp \left(-\frac{\Delta L_{\mathrm{A}}}{L_{\mathrm{A} 0}}\right)\left\{1-\exp \left(-\frac{\Delta L_{\mathrm{B}}}{L_{\mathrm{B} 0}}\right)\right\}}{1-\exp \left(-\frac{\Delta L_{\mathrm{A}}}{L_{\mathrm{A} 0}}-\frac{\Delta L_{\mathrm{B}}}{L_{\mathrm{B} 0}}\right)}
\end{aligned}
$$




\section{APPENDIX B}

Substituting $\Delta L_{\mathrm{A}}=r \Delta L_{\mathrm{B}}$ into (5) gives:

$$
\bar{q}_{\mathrm{mA}} *=\frac{\bar{q}_{\mathrm{mA} \infty}\left\{1-\exp \left(-\frac{r \Delta L_{\mathrm{B}}}{L_{\mathrm{A} 0}}\right)\right\}+\bar{q}_{\mathrm{mB} \infty} \exp \left(-\frac{r \Delta L_{\mathrm{B}}}{L_{\mathrm{A} 0}}\right)\left\{1-\exp \left(-\frac{\Delta L_{\mathrm{B}}}{L_{\mathrm{B} 0}}\right)\right\}}{1-\exp \left(-\frac{r \Delta L_{\mathrm{B}}}{L_{\mathrm{A} 0}}-\frac{\Delta L_{\mathrm{B}}}{L_{\mathrm{B} 0}}\right)}
$$

Setting $\Delta L_{\mathrm{B}} \rightarrow 0$ and using $\bar{q}_{\mathrm{m}} *=\bar{q}_{\mathrm{mA}} *$, (B-1) is rewritten as:

$$
\begin{aligned}
\bar{q}_{\mathrm{m}} *= & \frac{\bar{q}_{\mathrm{mA} \infty} \frac{r \Delta L_{\mathrm{B}}}{L_{\mathrm{A} 0}}+\bar{q}_{\mathrm{mB} \infty} \frac{\Delta L_{\mathrm{B}}}{L_{\mathrm{B} 0}}}{\frac{r \Delta L_{\mathrm{B}}}{L_{\mathrm{A} 0}}+\frac{\Delta L_{\mathrm{B}}}{L_{\mathrm{B} 0}}} \\
= & \frac{\bar{q}_{\mathrm{mA} \infty} r L_{\mathrm{B} 0}+\bar{q}_{\mathrm{mB} \infty} L_{\mathrm{A} 0}}{L_{\mathrm{A} 0}+r L_{\mathrm{B} 0}}
\end{aligned}
$$

Table 1 Fitting parameters used for the calculations shown in Fig. 3

\begin{tabular}{l|ccccc}
\hline & Brass & Copper & Aluminum & SUS 304 & SUS 316 \\
\hline $\bar{q}_{\mathrm{m} \infty}(\mathrm{mC} / \mathrm{kg})$ & -8.6 & -8.0 & -4.0 & 7.0 & 7.5 \\
$L_{0}(\mathrm{~m})$ & 0.95 & 0.78 & 0.63 & 1.00 & 1.13 \\
\hline
\end{tabular}

Table 2 Fitting parameters used for the calculations shown in Fig. 6 Case 1 (Brass $\rightarrow$ SUS 316)

\begin{tabular}{l|ccccc|c}
\hline $\bar{q}_{\mathrm{m} 0}(\mathrm{mC} / \mathrm{kg})$ & -8.6 & -7.1 & -5.2 & -3.1 & 0.0 & Average \\
\hline $\bar{q}_{\mathrm{m} \infty}(\mathrm{mC} / \mathrm{kg})$ & 6.7 & 6.8 & 6.8 & 7.2 & 7.5 & 7.0 \\
$L_{0}(\mathrm{~m})$ & 0.90 & 0.98 & 1.04 & 1.15 & 1.13 & 1.04 \\
\hline
\end{tabular}

Case 2 (SUS $316 \rightarrow$ Brass)

\begin{tabular}{l|ccccc|c}
\hline $\bar{q}_{\mathrm{m} 0}(\mathrm{mC} / \mathrm{kg})$ & 7.0 & 6.7 & 4.2 & 2.2 & 0.0 & Average \\
\hline $\bar{q}_{\mathrm{m} \infty}(\mathrm{mC} / \mathrm{kg})$ & -8.2 & -8.1 & -8.4 & -8.3 & -8.6 & -8.3 \\
$L_{0}(\mathrm{~m})$ & 0.76 & 0.76 & 0.89 & 0.97 & 0.95 & 0.87 \\
\hline
\end{tabular}




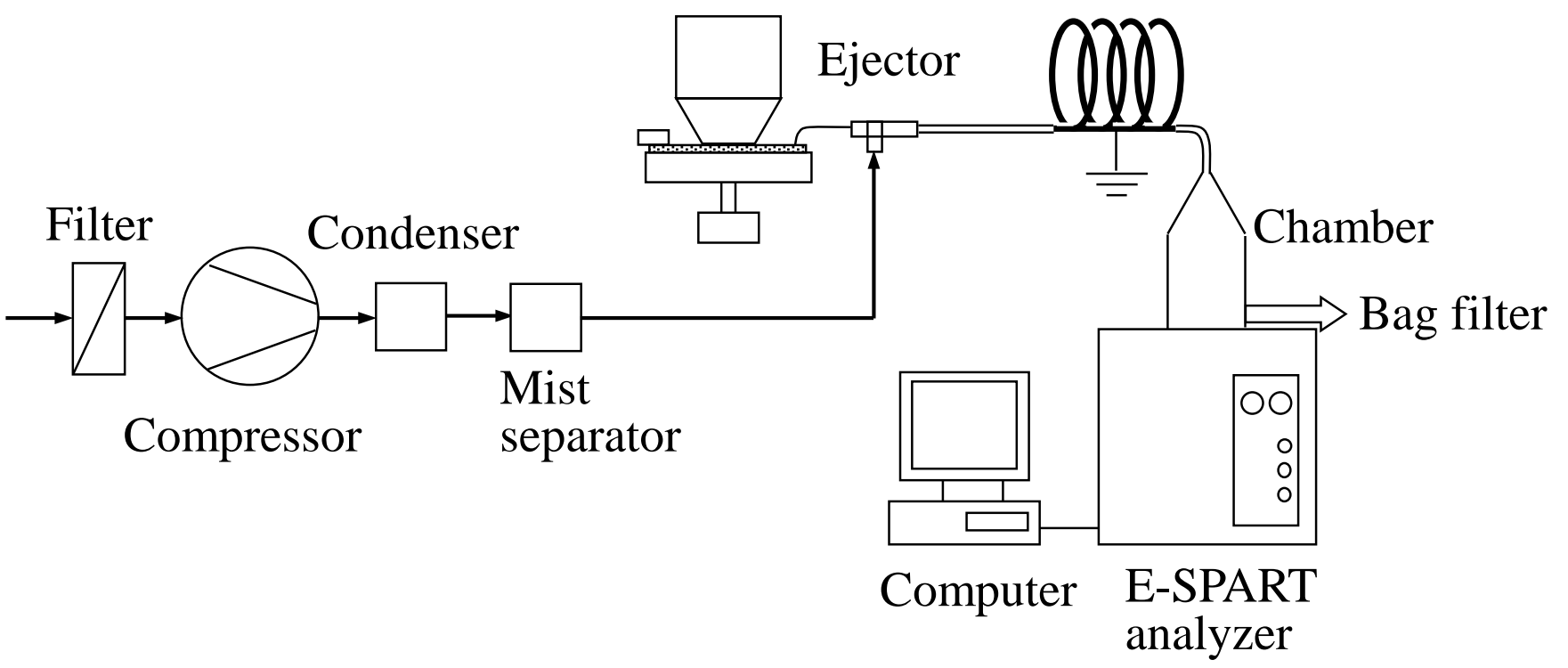

Figure 1. Experimental apparatus. 


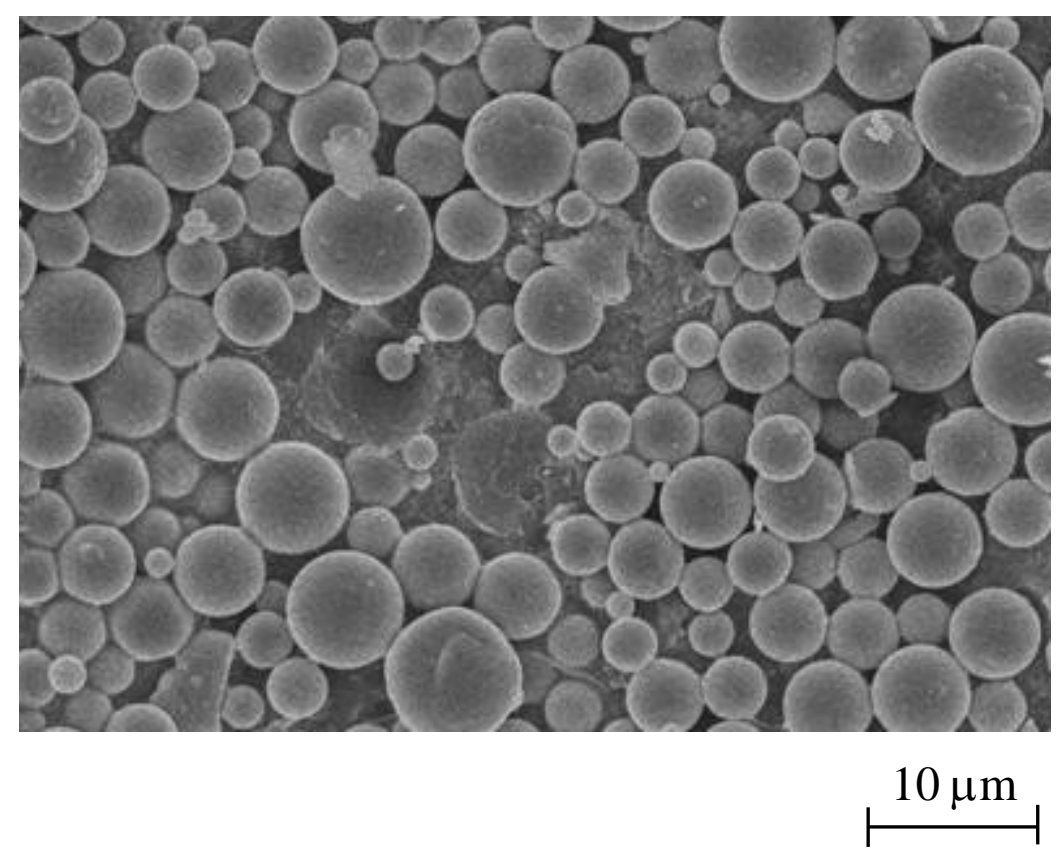

Figure 2. SEM image of powder used (alumina). 


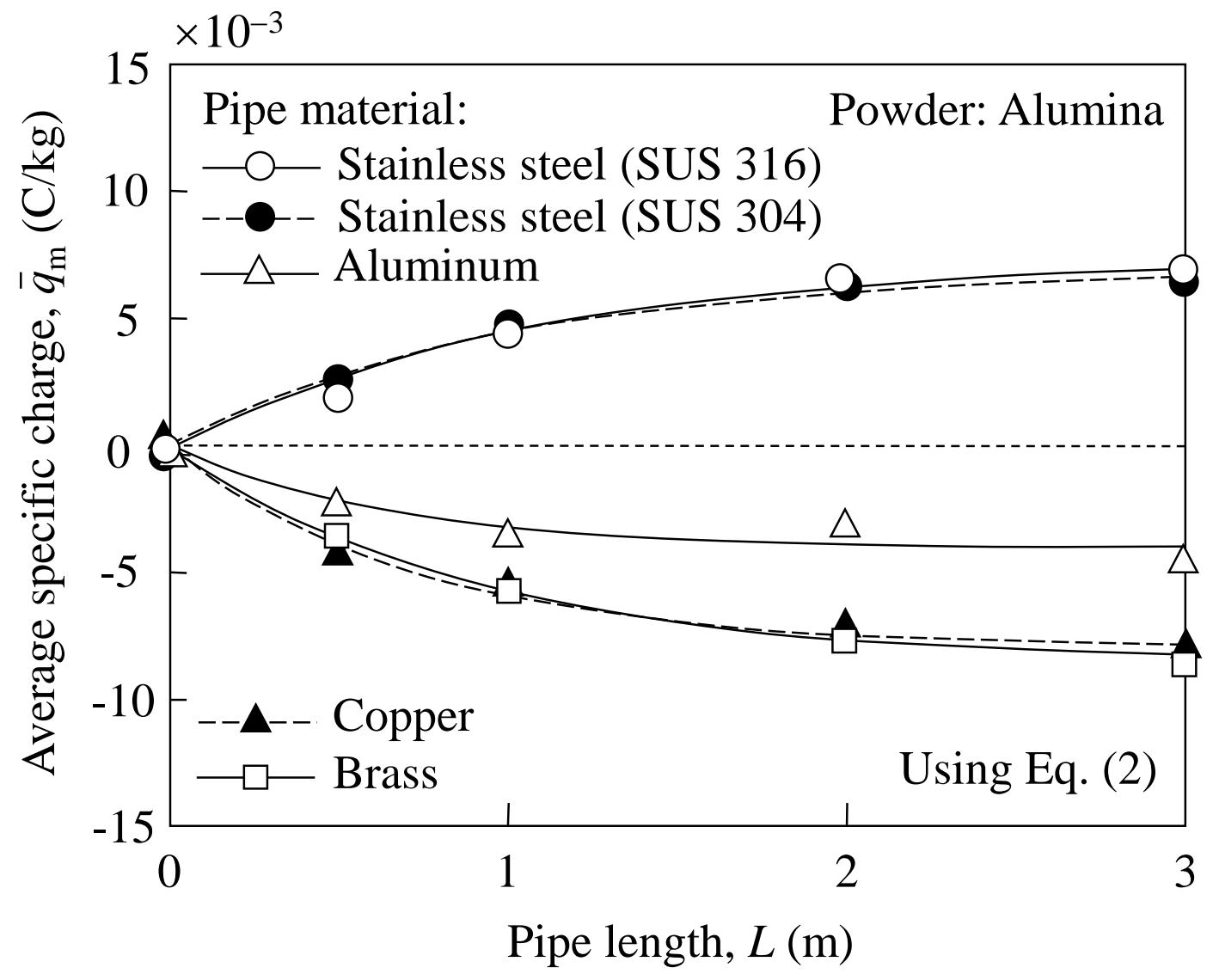

Figure 3. Relationships between average specific charge and pipe length [symbols are experimental data, curves are calculations using (2) and the fitting parameters are listed in Table 1]. 


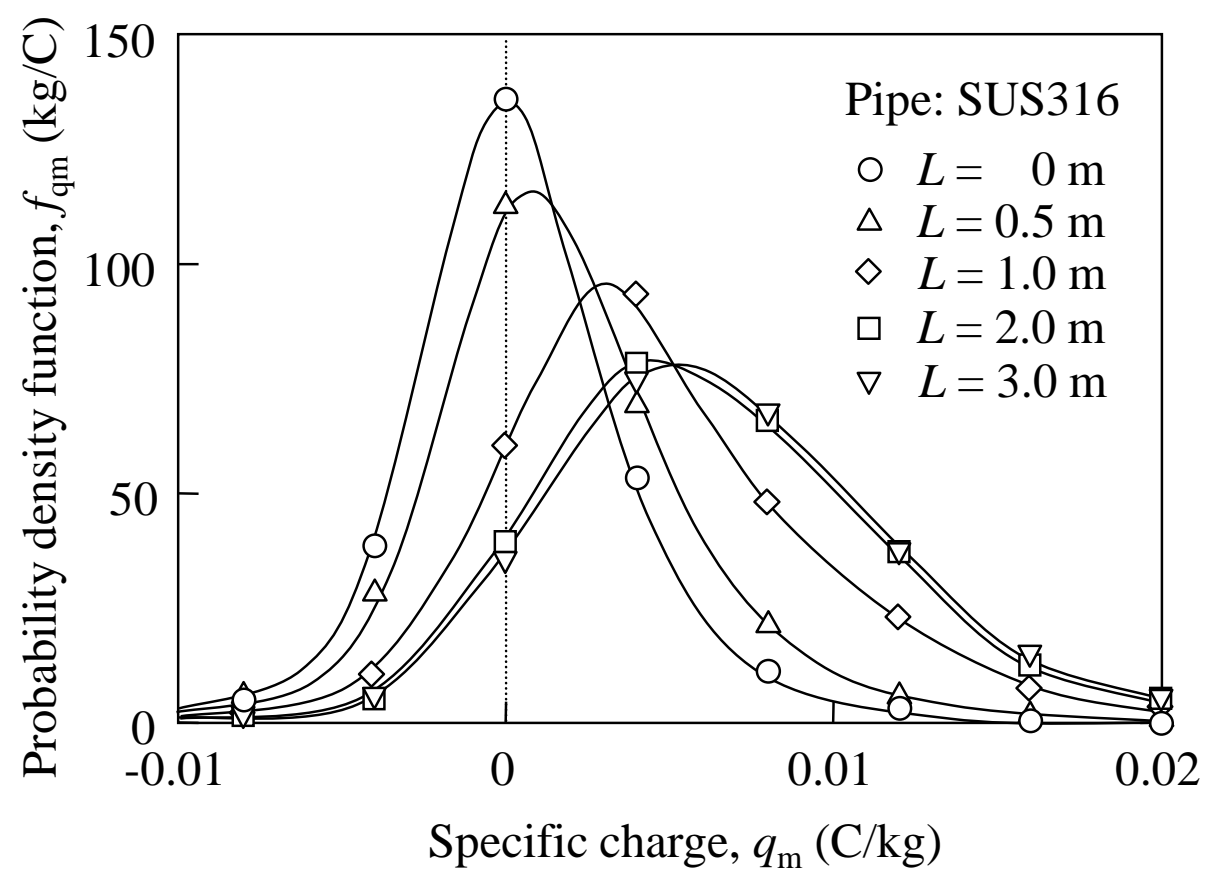

Figure 4. Effect of pipe length on charge distribution (specific charge). 


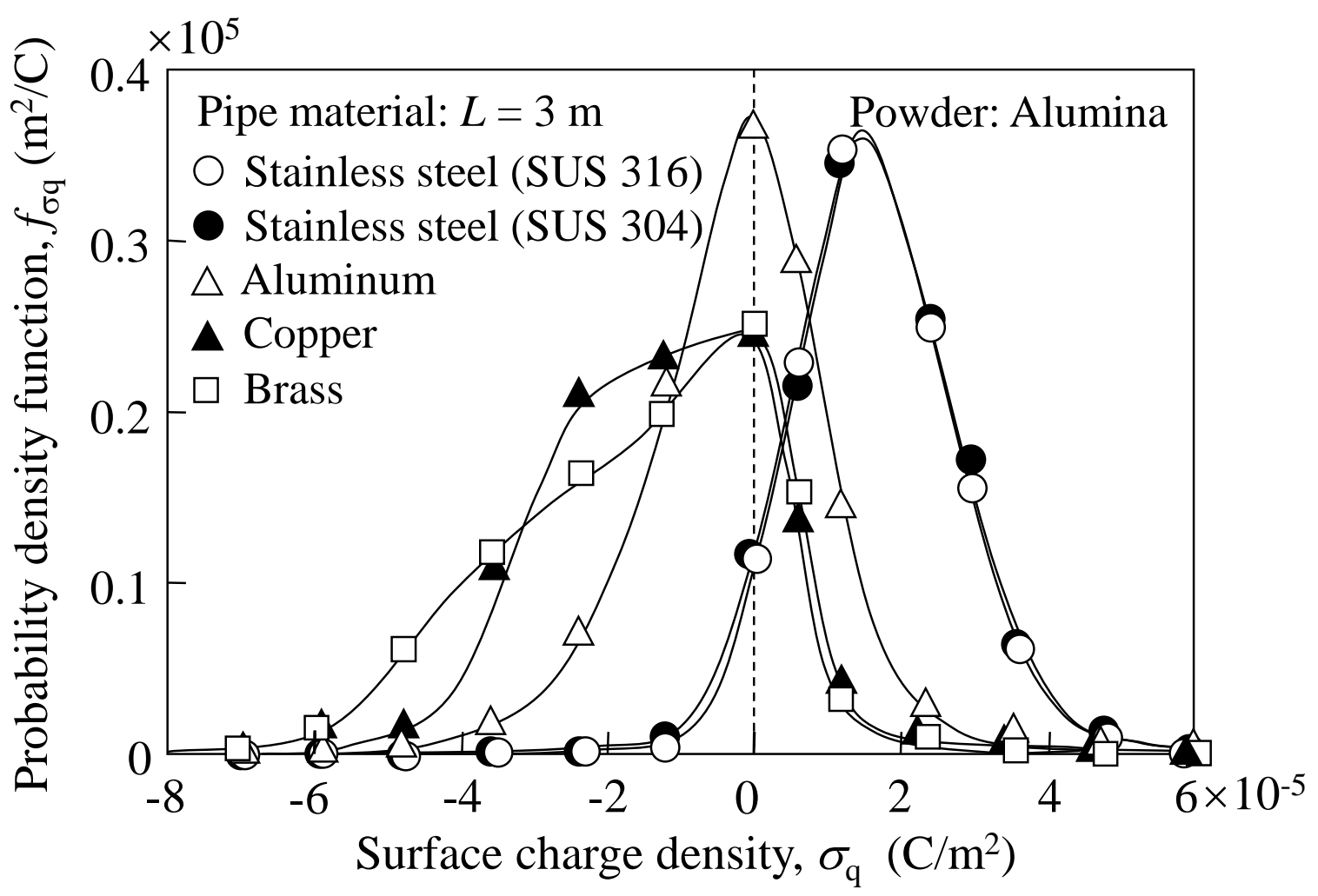

Figure 5. Effect of wall material on charge distribution (surface charge density). 


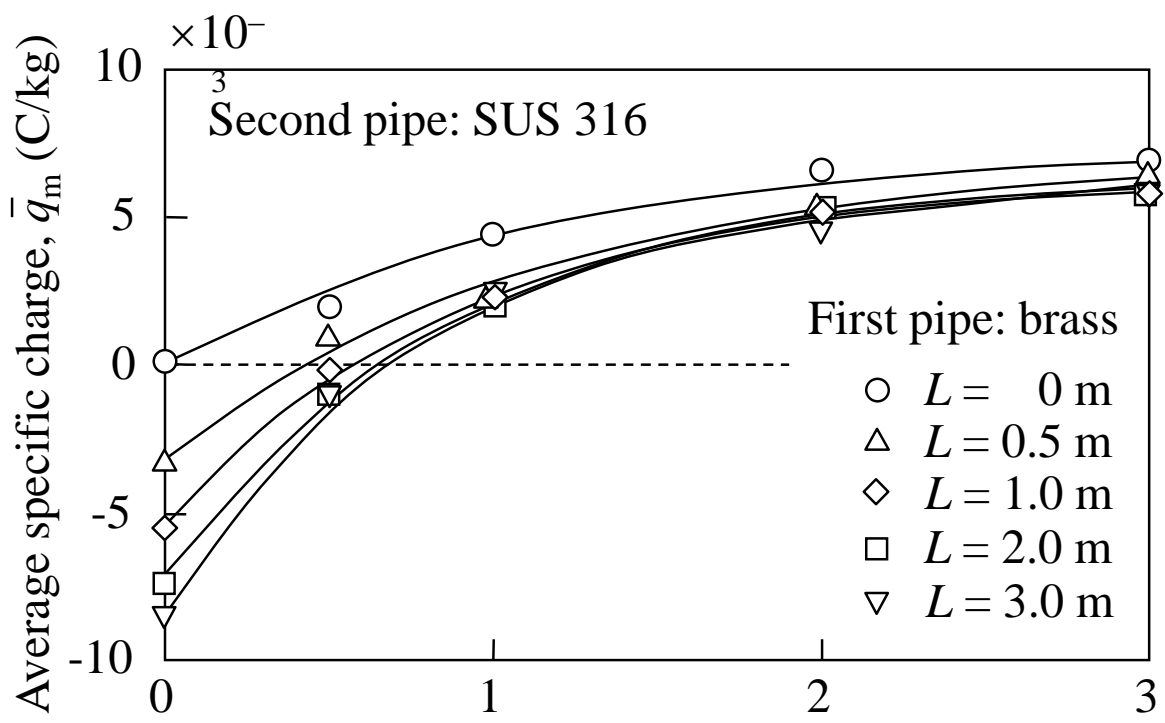

(a) Length of second pipe, $L$ (m)

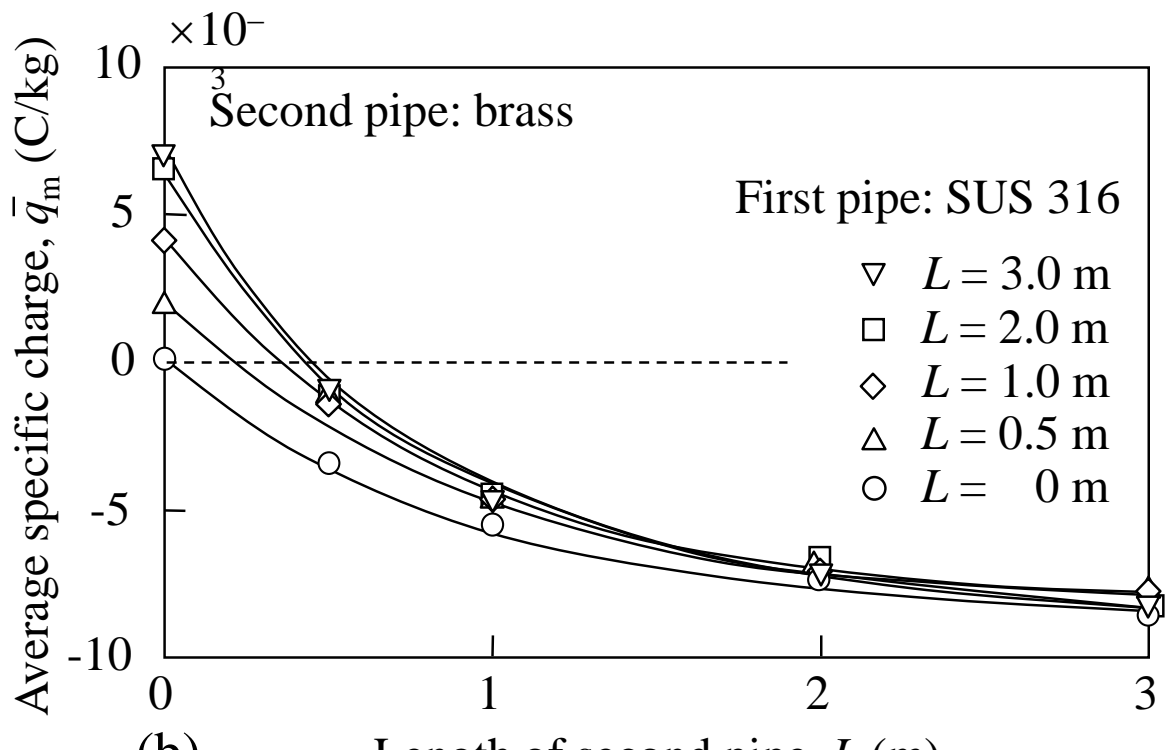

(b) Length of second pipe, $L$ (m)

Figure 6. Effect of initial charge on particle charging [symbols are experimental data; curves are calculations using (2) and the fitting parameters are listed in Table 2]. 

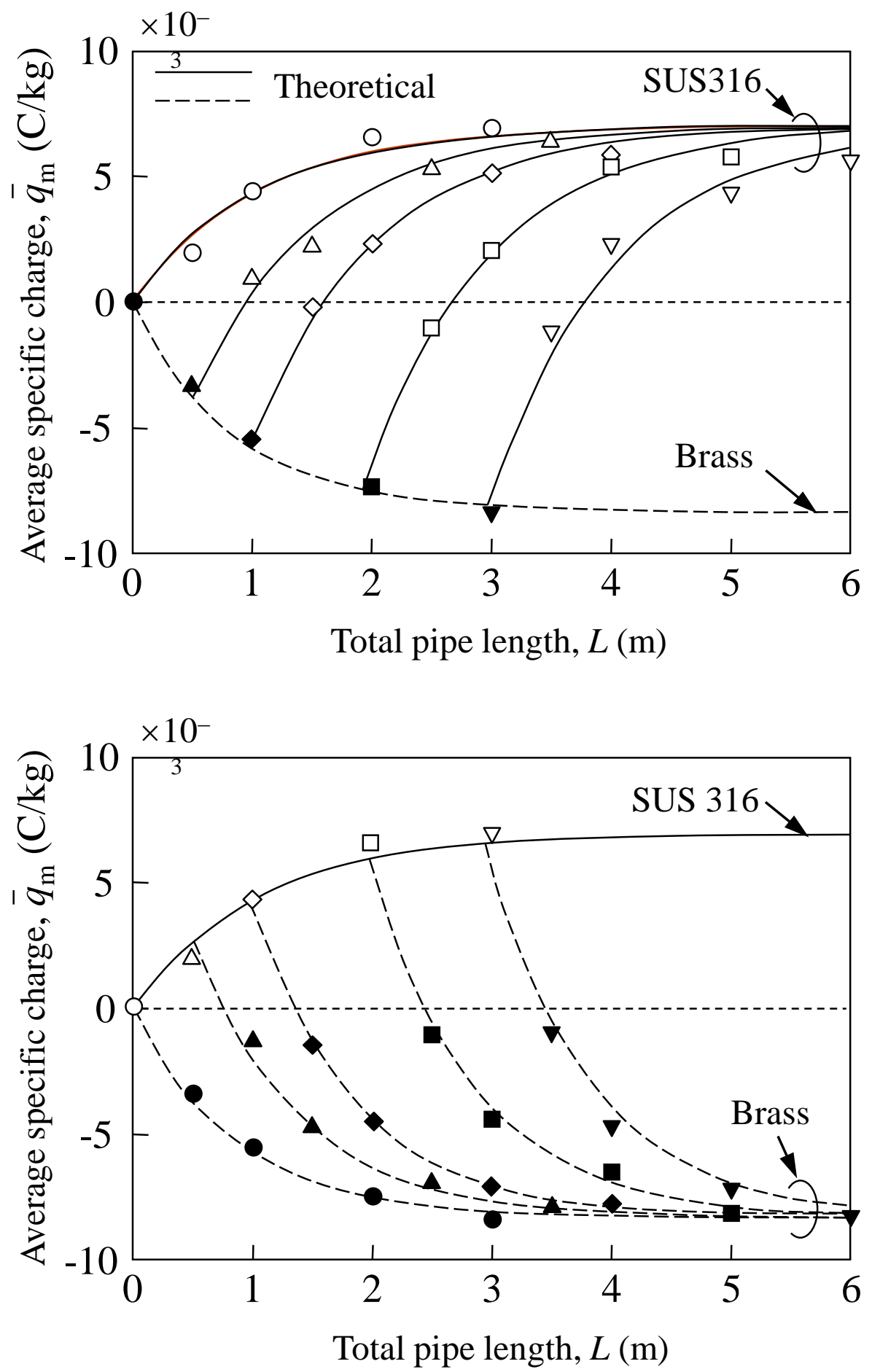

Figure 7. Comparison between experimental data and theoretical calculations [symbols are experimental data, curves are calculations using (2) with $\bar{q}_{\mathrm{m} \infty}=7.0 \mathrm{mC} / \mathrm{kg}, L_{0}=1.04 \mathrm{~m}$ for SUS 316 and $\bar{q}_{\mathrm{m} \infty}=-8.3 \mathrm{mC} / \mathrm{kg}, L_{0}=0.87 \mathrm{~m}$ for brass]. 


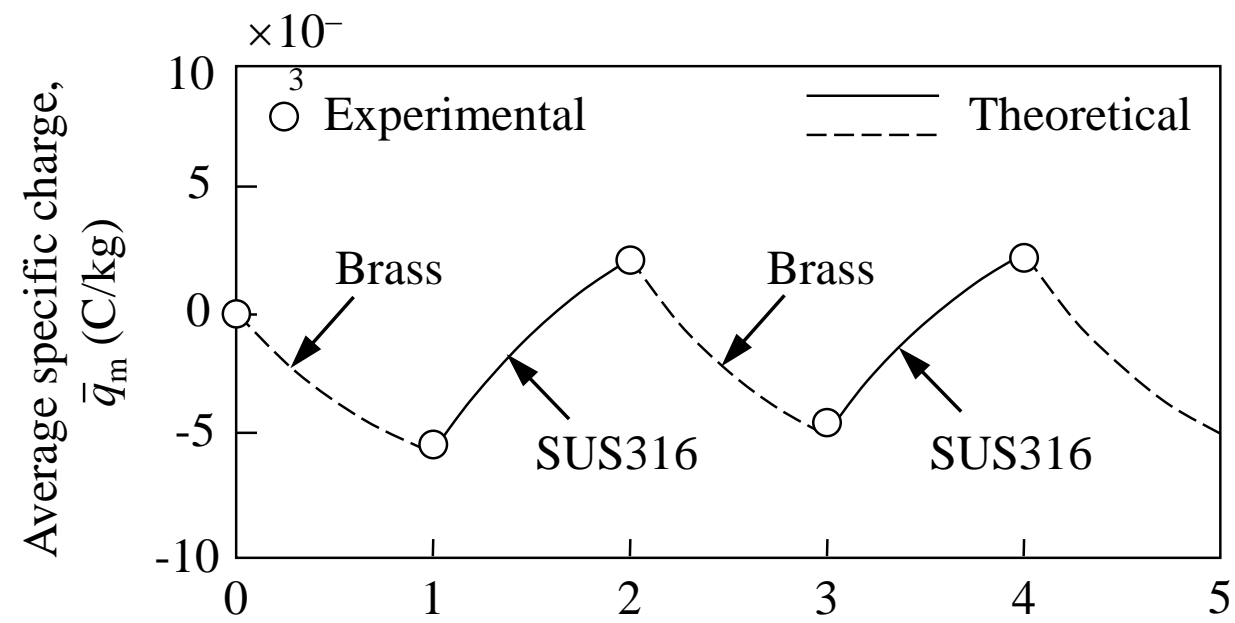

(a)

Total pipe length, $L(\mathrm{~m})$

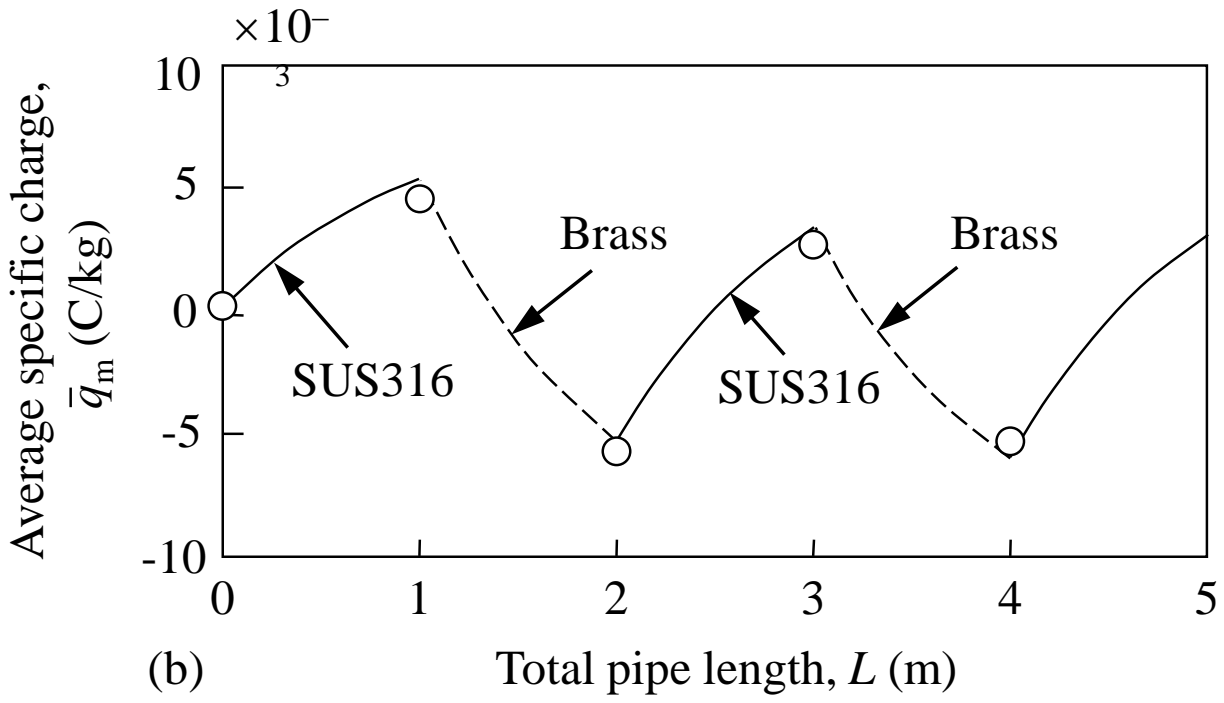

Figure 8. Control of particle charging by a system combining two different pipe materials - comparison between experimental data and theoretical calculations $\left(\Delta L_{\mathrm{A}}=\Delta L_{\mathrm{B}}=1 \mathrm{~m}\right)$. 

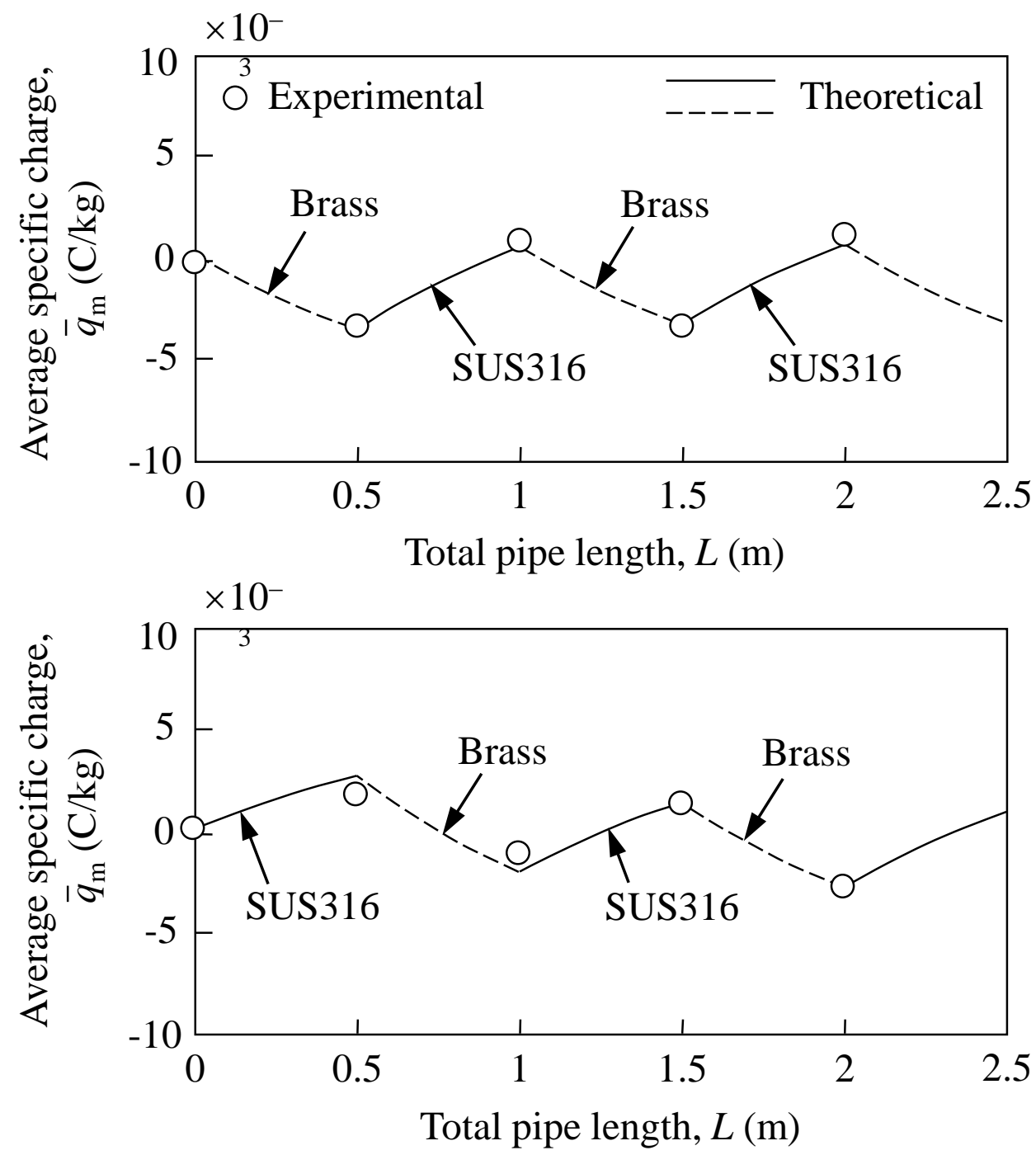

Figure 9. Control of particle charging by a system combining two different pipe materials -comparison between experimental data and theoretical calculations $\left(\Delta L_{\mathrm{A}}=\Delta L_{\mathrm{B}}=0.5 \mathrm{~m}\right)$. 


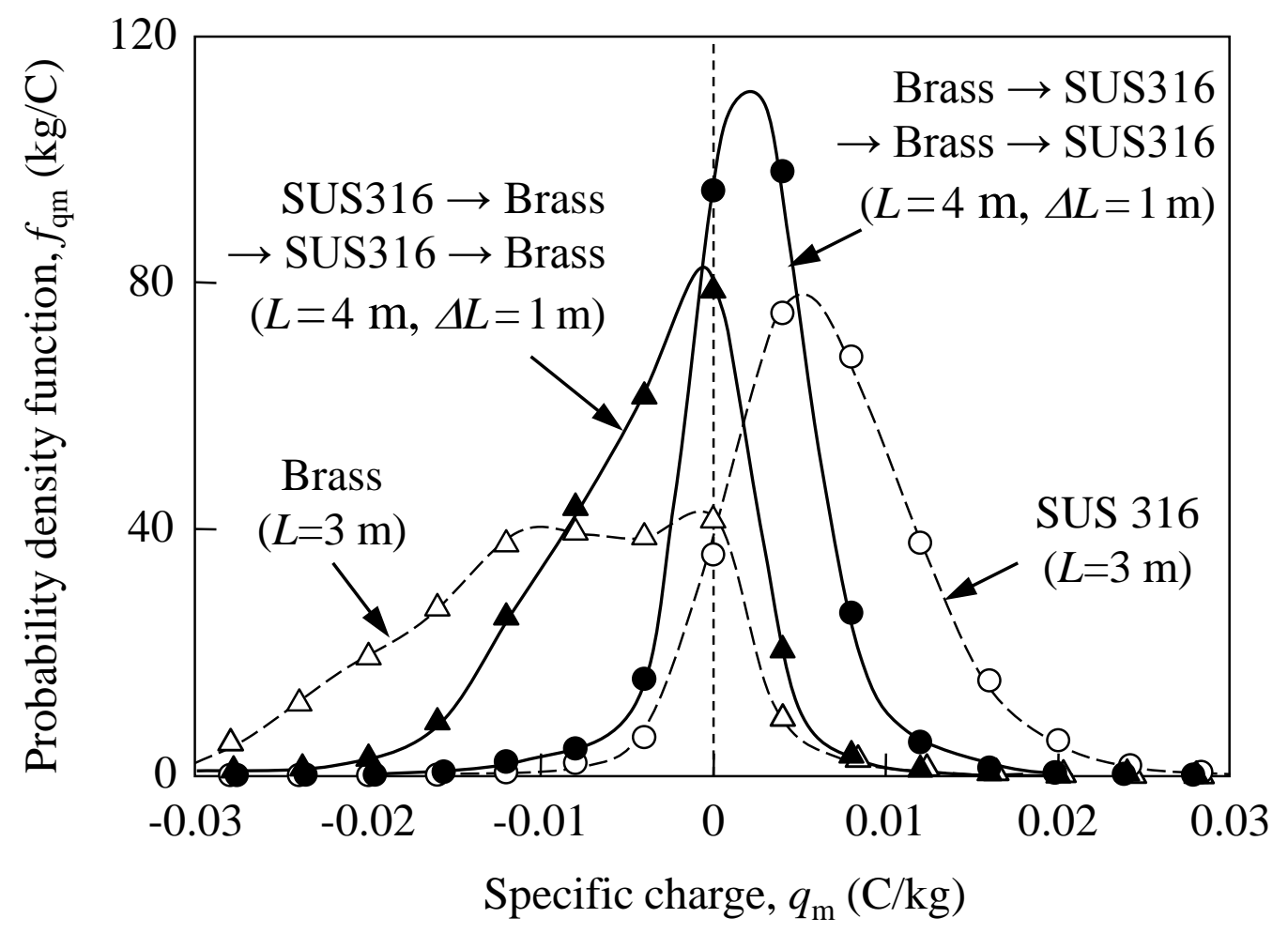

Figure 10. Effect of charge control on the distribution of specific charge. 